\title{
A Cost Benefit Analysis of Public Finance Towards Small, Medium and Microenterprise Development in South Africa
}

\author{
R Ncwadi \\ University of Fort Hare, Alice, South Africa
}

\begin{abstract}
Small businesses are recognized worldwide as a key element in economic and more particularly, industrial development. Most countries in the world have created special mechanisms to enhance and facilitate the creation and growth of Small Medium and Microenterprises (SMMEs). Despite the efforts by the government to establish a support structure for the small business sector in South Africa, to date this effort has not been successful. The failure rate of SMMEs is between $70 \%$ and $80 \%$ and millions of Rands are being lost on business ventures. The objective of this paper is to analyze the welfare impact of public expenditure on small, medium and microenterprises in South Africa. This research makes use of a cost benefit analysis on a sample of 226 small businesses which had received some form of non-financial support from local business service centers during the period 2001 to 2005. Using a benefit cost ratio as a decision-making criteria and subjective measurements on a three-point Likert scale, the results suggest that public finance on SMME promotion in the Eastern Cape yields positive social returns albeit that the small businesses still face a number of constraints. It is recommended that a holistic approach towards SMME support intervention is adopted, otherwise the social returns derived from public expenditure in SMME promotions will remain sub-optimal.
\end{abstract}

Keywords: Small Medium and Microenterprises (SMMEs), Local Business Service Centres (LBSCs), welfare, cost benefit analysis, benefit cost ratio, social discount rate

\section{Introduction}

The promotion of entrepreneurship and small business is an important priority of the government of South Africa. In an effort to support the development of Small Medium and Microenterprises (SMMEs) in South Africa, the government established a support structure for the small business sector. After the enactment of the national White Paper on small business, the Department of Trade and Industry (DTI) began the process of building new institutions to service the SMME economy (Manning, 1996, p. 36). To this end, the key institutions for the development of SMMEs were Ntsika Enterprise Promotion Agency (NEPA), Khula Enterprise Finance and Khula Credit Guarantee, the National Small Business Council, and Provincial SMME Desks (RSA, 1995). An important unit of NEPA was Business Development Services (BDS) which was set up in April 1995 to coordinate the evolution and development of the network of Local Business Service Centres (LBSCs). The LBSCs are accredited organizations which deliver non-financial business support and services to small and microenterprises. The majority of small businesses assisted by the LBSCs are start-ups rather than

R Ncwadi, Ph.D., Professor of Economics, Department of Economics, University of Fort Hare.

Correspondence concerning this article should be addressed to R Ncwadi, Department of Economics, University of Fort Hare, Private Bag X1314, Alice, 5700, South Africa. E-mail: rncwadi@ufh.ac.za. 
existing businesses (Rogerson, 1997, p. 10).

\section{The Problem and Its Setting}

Despite the efforts by government to establish a support structure for the small business sector in South Africa, this effort has not been as effective as was anticipated. Some small businesses continued to fail in South Africa. The failure rate of SMMEs is estimated to be between $70 \%$ and $80 \%$ and millions of Rands are being lost on business ventures (Van Eeden, Viviers, \& Venter, 2003). The failure of the small businesses despite the LBSC support provision led to a widespread belief that the LBSCs had little or no impact on small business (GEM, 2002, p. 7). The focus of most of the critics of the LBSCs has been based on an argument that the LBSCs failed to deliver effectively on their programmes (Bloch \& daze, 2000, p. 2).

The shortcomings with the LBSCs programmes were identified to firstly have been as a result of a lack of capacity within the LBSCs themselves in that some of the LBSCs staff were inexperienced in the task of advising entrepreneurs (Berry et al., 2002, p. 10). Secondly, the geographic coverage of the LBSCs system was inadequate. There was at best one LBSC in each of the larger towns, and in the majority of medium-sized as well as smaller towns there was none (Rogerson, 1997, p. 10). Even in the metro areas there were suburbs (or townships) with 100,000 or more inhabitants which had no centre nearby. In the rural areas and small towns, coverage was even more erratic (Rogerson, 1997, p. 10). Thirdly, apart from the spatial coverage, the other fundamental shortcoming of the LBSCs related to a lack of availability of easily understandable information. Fourthly and lastly, the LBSCs tended to service a wide range of businesses and were generally unable to mobilize the necessary expertise to provide more than a generic service to these businesses. The need to maximize service fees also resulted in a reluctance to refer clients to other suitable service providers as initially envisaged (Rogerson, 1997, p. 12).

Despite the shortcomings of the LBSCs, the public funds were still being invested in the LBSCs. For example, Ntsika's budget for 2000 was approximately 80 million rand of which approximately 12.5 million was allocated to LBSCs. Ntsika's 2001/2002 budget was almost half of the 2000/2001 budget at 43.6 million rand of which R8,240,289 was allocated to LBSCs and a further R1,084,440 to survivalist and micro enterprises, via other conduits. Khula's budget for it's two programmes that service the survivalist and micro-enterprise sectors, amounts to approximately R45 million for the year ending March 2003. This amount has been almost doubled for the year ending March 2004. The Enterprise Development Unit's budget for institutions for the financial year ending March 31, 2001 was R146 million. It was reduced to R104 million for the financial year ending March 31, 2003 (IDASA, 2003).

The above figures represent public sector funds and exclude donor funds, interest, fee income, and other forms of revenue. Donors committed R1.6 billion to SMME development for the period 1994-1999. By the end of 1999, R867 million of donor funds had been disbursed to NGOs. The remainder was committed to funding of existing projects. Fifty-five percent (R480 million) of the R867 million was disbursed to the “person-centred' survivalist sector, and therefore had poverty alleviation as its goal (ILO, 1999). These amounts do not take into account the funds secured by individual NGOs from overseas and local donors, which in most cases constitute by far the bulk of these NGOs' funds.

Given the above figures and the very limited state budget, it becomes crucial to look closely into the impact of LBSCs on the development of SMMEs. 


\section{Research Objectives}

The objective of this research was to analyse the effectiveness of the LBSCs interventions in the small businesses which participated in the LBSCs programmes. The period being reviewed in this study is 2001 to 2005. The main focus of analysis in this research is the public funds allocated to the LBSCs for SMME development and the resultant economic and social returns on this investment in the Eastern Cape.

\section{Hypotheses}

$\mathrm{H}_{0}$ : Public expenditure on the LBSCs does not yield positive social returns.

$\mathrm{H}_{\mathrm{a}}$ : Public expenditure on the LBSCs yields positive social returns.

\section{Research Methodology}

The hypotheses were tested primarily by a cost-benefit—analysis. The idea of cost-benefit analysis (CBA) for example, is to measure the net advantages of a capital investment project in terms of society's net utility gains (welfare economics) (Mullins, 2002). The effectiveness of the LBSCs interventions was assessed firstly by measuring subjective perceptions of the respondents on improvements attributable to the LBSC programs and the objective measurement of post-assistance business performance, namely, annual turnover and employment creation. The subjective measures were based on a three-point Likert scale of 1-3 (1 = no impact; 2 = minor impact; and 3 = major impact).

The respondents were asked to state the percentage annual growth of the turnovers from 2002 to 2005 that could be attributed to the LBSCs support interventions. The percentages of annual turnovers attributed to the LBSCs support interventions were used to adjust the annual turnovers of the small over the period under review. Using the adjusted annual turnovers as a benefit of LBSCs interventions is in line with the work of Chrisman and McMullan who evaluated small business interventions using both client satisfaction and economic performance measures in terms of annual turnovers of the businesses (Chrisman \& McMullan, 2000, p. 37).

The costs comprised of the annual budgets allocated by Ntsika to the LBSCs for SMME development and the fees paid by the respondents to access the LBSCs services. After the costs and benefits of LBSCs interventions were identified and quantified, the next step was to evaluate these costs and benefits in a time dimension (Nas, 1996). The project costs and benefits streams were discounted to present values (Mullins, 2002, p. 44). A social discount rate of eight percent was used as recommended by the Conningarth Economists (Conningarth Consultants, 2007). A change in social welfare of in SMME promotion in the Eastern Cape was measured by deducting the summation of social costs from social benefits.

A discounted benefit cost ratio (BCR) was used as a decision-making criteria. The discounted BCR is defined as the ratio of the present value of the benefits relative to the present value of the costs (Kirkpatric \& Weiss, 1996). The criterion for acceptance of a project is that the discounted BCR must exceed one.

\section{Sample Selection}

The LBSCs were approached to provide a list of the small businesses which accessed LBSCs services in 2001. The purpose was to assess the performance of these small businesses over a period 2002-2005.

This list from NMMU/ABSA Small Business Unit in Port Elizabeth contained a total number of 105 clients. The aim was to reach all 105 clients contained in the list. This database was, however, not reliable as many contact details had changed. Consequently, a total number of 81 respondents could be reached for 
interviewing. Of the 81 respondents, 20 intimated that they were no longer running businesses but were on full time employment. The reason for this was that they could not access the necessary finances to start their businesses.

A list containing 157 clients was obtained from COMSEC in Port Elizabeth. Due to incorrect and/or changed contact numbers, only 87 clients could be reached for interviewing. Of the 87 clients, only 58 questionnaires were usable. Of the remaining 29 respondents, 15 intimated that they were no longer in business due to finances as well as infrastructural constraints and 14 questionnaires could not be used as there was crucial data missing.

Out of a list of 60 small businesses who were assisted in Mdantsane Small Business Service Centre, only 43 small businesses were available and willing to be interviewed. The interviews were conducted on the premises of the Mdantsane Small Business Service Centre. The remainder (20) did not respond to the invitation. In Umtata, a total number of 74 small businesses out of 100 that were assisted in 2001 were approached and interviewed. The remainder (26) could not be traced due to change of addresses.

The total number of respondents included in the sample amounts to 226.

\section{Descriptive Results}

Gender. More than half (54\%) of the respondents were females as compared with their male counterparts (46\%) (see Table 1).

Table 1

Gender

\begin{tabular}{llc}
\hline Gender & $N$ & Percent (\%) \\
\hline Male & 103 & $46 \%$ \\
Female & 123 & $54 \%$ \\
Total & 226 & $100 \%$ \\
\hline
\end{tabular}

Note. Source: Survey data (2008).

Age groups. Thirty-three percent of the respondents were within the age group of 31-40 years, followed by $29 \%$ of those who were within the age group of 41-50 years of age. Those who were within the age group of 21-30 years made up 27\%, whilst those between the ages of 51-60 made up a mere $8 \%$ followed a small percentage of $3 \%$ of those who were 60 years old and above (see Table 2).

Table 2

Age Groups

\begin{tabular}{lcc}
\hline Age groups & $N$ & Percent (\%) \\
\hline $21-30$ & 75 & $33 \%$ \\
$31-40$ & 61 & $27 \%$ \\
$41-50$ & 66 & $29 \%$ \\
$51-60$ & 18 & $8 \%$ \\
$61+$ & 6 & $3 \%$ \\
Total & 226 & $100 \%$ \\
\hline
\end{tabular}

Note. Source: Survey data (2008).

Education levels of the respondents. More than half (51\%) of the respondents had grades 8-10 levels of education, whilst almost $14 \%$ had grades $11-12$ levels of education. Only $12 \%$ had tertiary qualifications whilst 
only a mere $8 \%$ had post-matric certificates in fashion design, decorations, fashion design and construction. One percent of the respondents had no education, whilst 13\% had grades 1-7 (see Table 3).

Table 3

Education Levels of the Respondents

\begin{tabular}{lrc}
\hline Education levels & $N$ & Percent (\%) \\
\hline None & 5 & $2 \%$ \\
Grades 1-7 & 29 & $13 \%$ \\
Grades 8-10 & 115 & $51 \%$ \\
Grades $11-12$ & 32 & $14 \%$ \\
Post-matric certificate & 18 & $8 \%$ \\
Tertiary & 27 & $12 \%$ \\
Total & 226 & $100 \%$ \\
\hline
\end{tabular}

Note. Source: Survey data (2008).

Industrial sectors. Approximately 33\% of small businesses were in construction industry, followed by transport, storage, and communication which made up 22\%. Fifteen percent of the respondents were in community, social, and personal services. The manufacturing sector made up about $10 \%$. The remaining sectors were agriculture (6\%), wholesale and retail (8\%), electricity, gas and water (3\%), and finance, insurance, real estate, and business services (3\%) (see Table 4).

Table 4

Industrial Sectors

\begin{tabular}{lrr}
\hline Industrial sectors & $N$ & Percent (\%) \\
\hline Agriculture & 14 & $6 \%$ \\
Construction & 74 & $33 \%$ \\
Wholesale \& Retail & 18 & $8 \%$ \\
Manufacturing & 23 & $10 \%$ \\
Transport \& Communication & 50 & $22 \%$ \\
Electricity, gas \& water & 7 & $3 \%$ \\
Community, social \& personal services & 33 & $15 \%$ \\
Finance, insurance, real estate \& business services & 7 & $3 \%$ \\
Total & 226 & $100 \%$ \\
\hline
\end{tabular}

Note. Source: Survey data (2008).

\section{Cost-Benefit Analysis (CBA)}

CBA provides a protocol to measure allocative efficiency in the economy. CBA is concerned exclusively with comparisons of direct benefits and costs to society created by an investment project. CBA is ideally suited for the evaluation of capital projects, i.e., projects which require immediate capital expenditure but which realise net benefits over time

\section{Respondents Estimated Annual Turnovers: 2001-2005}

The respondents were asked to estimate their annual turnovers from 2001 to 2005 . They were then asked to estimate the percentage of the annual turnover that could be attributed to the LBSCs interventions. These annual turnovers were then adjusted by the estimated percentage contribution of the LBSCs. The summation of 
the annual turnovers and the adjusted turnovers are illustrated in Table 5.

Table 5

Summation of the Estimated Annual Turnovers and Adjusted Turnovers: 2001-2005

\begin{tabular}{llcc}
\hline Years & $\begin{array}{l}\text { Annual } \\
\text { turnovers } \\
\text { (in Rands) }\end{array}$ & $\begin{array}{l}\text { \% contribution attributed } \\
\text { to the LBSC }\end{array}$ & $\begin{array}{l}\text { Sum of adjusted annual turnovers } \\
\text { (in Rands) }\end{array}$ \\
\hline 2001 & 470,880 & 0 & 470,880 \\
2002 & 823,400 & 97.2 & 359,020 \\
2003 & $1,345,215$ & 97.2 & 579,669 \\
2004 & $1,997,981$ & 97.2 & 863,533 \\
2005 & $2,621,610$ & 97.2 & $1,117,002$ \\
\hline
\end{tabular}

Note. Source: Survey data (2008).

The costs were derived from public expenditure on the LBSCs during the period under review. Each LBSC was asked to state the amount received from the government which was targeted towards SMME training. These costs are illustrated in Table 6.

Table 6

Government Subsidies Targeted Towards SMME Training in LBSCs and Fees Paid for Accessing Some of the Services (in Rands)

\begin{tabular}{lrrrrr}
\hline LBSCs & \multicolumn{1}{c}{2001} & \multicolumn{1}{c}{2002} & \multicolumn{1}{c}{2004} & \multicolumn{1}{c}{2005} \\
\hline LBSC A & & 75,000 & 134,000 & 113,000 & 263,000 \\
LBSC B & 75,000 & 175,000 & 250,000 & 250,000 & 250,000 \\
LBSC C & 175,000 & 45,000 & 50,000 & 65,000 & 70,000 \\
LBSC D & 40,000 & 110,000 & 120,000 & 140,000 & 150,000 \\
Sum of the fees paid & 100,000 & 0 & 0 & 0 & 0 \\
by respondents & 68,570 & 405,000 & 554,000 & 568,000 & 733,000 \\
Total & 458,570 & & &
\end{tabular}

Note. Source: Survey data (2008).

Since the LBSCs interventions were affected in 2001, the stream of benefits was assumed to have been realised from 2002. The adjusted annual turnovers were summed as follows:

$$
\sum R 359,020^{(2002)}+R 579,669^{(2003)}+R 863,533^{(2004)}+R 1,117,002^{(2005)}=R 2,919,224
$$

Sum of the costs (2001-2005):

$$
\sum R 458,570^{(2001)}+R 405,000^{(2002)}+R 554,000^{(2003)}+568,000^{(2004)}+733,000^{(2005)}=R 2,718,570
$$

Change in social welfare using the equation:

$$
\Delta S W=\sum_{j=1}^{k} \mathrm{Bj}-\sum_{j=1}^{m} \mathrm{Cj}=R 2,929,224-R 2,718,570=R 210,654
$$

This implies that the promotion of SMMEs through the LBSCs over the period 2001-2005 amongst the selected sample led to a social welfare gain of R210,654.

After the costs and benefits were identified, the next step was to evaluate these costs and benefits in a time dimension.

\footnotetext{
${ }^{1}$ Real names of the LBSCs have not been mentioned in order to maintain confidentiality.
} 
The following formulas were used for discounting costs and benefits:

\section{Present Value of Costs}

$$
P V C=\sum \frac{c_{t}}{(1+r)^{t}}
$$

where:

$$
\begin{aligned}
& P V C=\text { Present value cost; } \\
& \sum C_{t}=\text { Sum of the costs; } \\
& r=\text { discount rate of } 8 \% \text {; } \\
& t=\text { period. } \\
& P V C=R 458,570+R 405,000\left(\frac{1}{1+0.08}\right)+R 554,000\left(\frac{1}{1+0.08}\right)^{2}+R 568,000\left(\frac{1}{1+0.08}\right)^{3} \\
& +R 733,000\left(\frac{1}{1+0.08}\right)^{4}=R 2,298,209
\end{aligned}
$$

\section{Present Value of Benefits}

$$
P V B=\sum \frac{B_{t}}{(1+r)^{t}}
$$

where:

$P V B=$ Present value benefits;

$\sum B_{t}=$ Sum of benefits;

$r=$ discount rate of $8 \%$;

$t=$ period.

$$
\begin{gathered}
P V B=R 359,020\left(\frac{1}{1+0.08}\right)+579,669\left(\frac{1}{1+0.08}\right)^{2}+R 863,533\left(\frac{1}{1+0.08}\right)^{3} \\
+R 1,117,002\left(\frac{1}{1+0.08}\right)^{4}=R 2,335,929 \\
N P V=P V B-P V C
\end{gathered}
$$

That is:

$\mathrm{NPV}=R 2,335,929-R 2,298,209=R 37,720$

The NPV is defined as the discounted sum of all net benefits (i.e., the difference between the benefits and the costs) over the economic life of the project. The net present value (NPV) and the discounted benefit cost ratio (BCR) were used as a decision making criteria.

The benefit/ cost ratio was determined as follows:

$$
\mathrm{BCR}=\sum_{t=0}^{n} \frac{B^{t}}{(1+i)^{t}} \div \sum_{\mathrm{t}=0}^{\mathrm{n}} \frac{C^{t}}{(1+i)^{t}}=R 2,335,929 / R 2,298,209=1.02
$$

The decision criteria are the Net Present Value (NPV) and Benefit cost ratio (BCR). The NPV is greater than 0 and that the BCR is above 1, implying that the public expenditure in SMME promotion through LBSCs during the period under review was both economically and financially viable.

\section{Sensitivity Analysis}

Sensitivity analysis is carried out to determine how a change in any one or more variables will affect the value of the criteria used, namely, the BCR. In this case, the average real interest rate of 7.3\% (2001-2005) was 
used. The following formulas were used for discounting costs and benefits:

\section{Present Value of Costs (Sensitivity Analysis)}

$$
\begin{gathered}
P V C=\sum \frac{C_{t}}{(1+r)^{t}} \\
\text { PVC }=R 458,570+\mathrm{R} 405,000\left(\frac{1}{1+0.073}\right)+R 554,000\left(\frac{1}{1+0.073}\right)^{2}+R 568,000\left(\frac{1}{1+0.073}\right)^{3}+733,000 \\
\left(\frac{1}{1+0.073}\right)^{4}=R 2,329,952.98
\end{gathered}
$$

\section{Present Value of Benefits (Sensitivity Analysis)}

$$
\begin{gathered}
P V B=\sum \frac{B_{t}}{(1+r)^{t}} \\
\operatorname{PVB}=R 359,020\left(\frac{1}{1+0.073}\right)+R 579,669\left(\frac{1}{1+0.073}\right)^{2}+R 863,533\left(\frac{1}{1+0.073}\right)^{3}+R \quad 1,117,002 \\
\left(\frac{1}{1+0.073}\right)^{4}=R 2,379,742.14
\end{gathered}
$$

$$
\begin{gathered}
\mathrm{NPV}=R \text { 49,789.16 } \\
\mathrm{BCR}=\mathrm{PVB} / \mathrm{PVC}=R 2,379,742.14 / R 2,261,382.98=1.05
\end{gathered}
$$

Even at the lower discount rate of $7.3 \%$, the NPV remains above zero and the BCR greater than 1 . It can be concluded therefore that the project was worthwhile. The results of the CBA are also in line with the subjective perceptions of the respondents on the impact of the LBSCs on the small businesses during the period under review. Based on the results of the CBA, we therefore reject the null hypothesis in favor of the alternative one.

\section{Policy Implications, Conclusions, and Recommendations}

The promotion of enterprise development has been a priority of the democratic government since it assumed power in 1994. In March 1995, the White Paper on the promotion of small businesses in South Africa was promulgated in parliament. The White Paper formed the basis for government led SMME development programme. The primary objective of the White Paper was to create an enabling environment for small businesses within the context of a modernizing economy and increasing international competition, and to facilitate greater equalization of income, wealth and economic opportunities; create long-term jobs; stimulate economic growth; strengthen the cohesion between small enterprises; and level the playing fields between bigger and smaller businesses. However, the results of this study prove that the LBSCs had positive welfare effects on the economy. This is against a widespread belief that the LBSCs had not played a significant role in welfare improvement in the economy of the Eastern Cape. Notwithstanding, there has been a number of challenges which rendered the benefits from LBSCs interventions suboptimal, namely, access to bank loans, labour relations, HIV/Aids, lack of infrastructural facilities, crime and macroeconomic instability. However, these obstacles fall beyond the scope of the LBSCs.

These challenges call for attention of the policy makers as regards SMME support provision in the Eastern Cape. Although there had been some policy changes with regard to SMME support provision in South Africa 
since 2004, there has been no fundamental shift in terms of the approach towards SMME promotion. The approach is still based on a linear approach wherein it is assumed that once a small business has been through an LBSC programme that small business will become viable and successful. The results of this research reject such a notion. LBSCs alone are not sufficient to boost the SMME sector in South Africa. It is clear, therefore, that small business support intervention should be based on an integrated approach wherein all relevant stakeholders play their parts. There is a pressing need for an integrated SMME development strategy in order to address challenges facing the SMMEs. The existing national small business strategy is a useful first step but does not go far enough to meeting the specific needs and constraints that face the SMMES in South Africa, particularly in disadvantaged communities.

Based on the findings of this research, it can be concluded that the public expenditure on SMME promotion in the Eastern Cape yielded positive social returns. Notwithstanding, it is recommended that a holistic approach towards SMME support intervention is adopted, otherwise the social returns derived from public expenditure in SMME promotions will remain sub-optimal.

\section{References}

Berry, A., Von Blottnitz, M., Cassim, C., Kesper, A., Rajaratnam, B., \& Van Seventer, D. E. (2002). The economics of SMMEs in $S A$. Pretoria: TIPS Report.

Bloch, R., \& Daze, S. (2000). A review of the South African local business service centre programme: Current status, future prospects. Final Report for International Development Research Centre-Regional Office Southern Africa.

Chrisman, J., \& McMullan, W. E. (2000). A preliminary assessment of outsider assistance as a knowledge resource: The long-term impact of new venture counseling. Entrepreneurship Theory and Practice, 24(3), 37-53.

Conningarth Consultants. (2007). A manual for cost benefit analysis in South Africa with specific reference to water resource development (Prepared for Water Research Commission. Report No. TT305/07).

GEM. (2002). South African executive report. Cape Town: The Graduate School of Business: University of Cape Town.

IDASA. (2003). Poverty alleviation: Beyond the national small business strategy. Occasional Paper: Institute for Democracy in Africa.

ILO. (1999). The ILO's response to the financial crisis in East and South-East Asia. The Social Impact of the Asian Financial Crisis: An ILO Governing Body Symposium, GB.274/4/4, 274th Session, Geneva.

Kirkpatric, K., \& Weiss, J. (1996). Cost benefit analysis and project appraisal for developing countries. London: Edward Elgar.

Manning, C. (1996). Market access for small and medium-sized producers in South Africa: The case of the furniture industry (Unpublished Ph.D. dissertation, University of Sussex, Brighton).

Mullins, D. (2002). A manual for CBA in South Africa with specific reference to water resource department: Prepared for the water research commission (Report No. TT 17702/02). Pretoria: Conningarth Economists.

Nas, T. F. (1996). Cost benefit analysis: Theory and application. London: Sage.

Republic of South Africa (RSA). (1995). National strategy for the development and promotion of small business in South Africa. Cape Town: White Paper of the DTI.

Rogerson, C. M. (1997). SMMEs and poverty in South Africa. Input Report for the National Project on Poverty and Inequality.

Van Eeden, S., Viviers, S., \& Venter, D. (2003). A comparative study of selected problems encountered by small businesses in the Nelson Mandela, Cape Town and Egoli metropolis. Management Dynamics Volume, 12(3), 13-23. 